\title{
COMMENTARY: Youth, economic hardship, and the worldwide Great Recession
}

\section{Robert Crosnoe}

University of Texas at Austin

crosnoe@austin.utexas.edu

(Received March 2014 Revised April 2014)

Commenting on the plight of young people during the Great Recession, economist Richard Freeman remarked (Estes, 2011), "These people will be scarred, and they will be called the 'lost generation'." These words are quite stark, but they speak to the gravity of the situation at hand, the high stakes involved-not just for young people but for society as a whole.

Whether today's youth are indeed scarred and lost (or not) has generated a great deal of social and behavioral research in the last several years. This attention is certainly not surprising. How young people fared during this economic downturn is of great importance to policy and practice; for example, economics research can quantify who has been hardest hit, who is the most vulnerable in the future, who needs the most help, and what the price tag might ultimately be. At the same time, this issue has broad theoretical significance across disciplines. Capturing the interplay of macro-level societal trends and micro-level personal experiences, it embodies the very core of the sociological imagination, life course theory, human ecology, and many other perspectives in sociology, demography, developmental science, and economics (Grusky, Western, \& Wimer, 2012).

The four articles in this Special Section are part of a new tradition of Great Recession research focused on children, adolescents, and young adults. They grew out of a series of activities and meetings (of which I was a part) funded by the Society for Research in Child Development, the Economic and Social Research Council (UK), and other organizations across several countries, as part of the growing concern over the very possibility that we might have a lost generation (or lost generations) on our hands. Like so many studies of the effects of social change on the individual life course (Silbereisen, 2005; Elder,
http://dx.doi.org/10.14301/Ilcs.v5i2.296

1999), the story emerging from these four articles is a complicated one. Yes, the Great Recession has been bad for young people in general, but it has been far worse for some than others. Moreover, the risks of the Great Recession can only be understood at the intersection of contextual variation (in terms of current circumstances and past histories) and individual differences.

From this highly general conclusion, I want to draw out several themes for further discussion from this notably interdisciplinary and cross-national enterprise. The first set of themes concerns what was found in the four studies, and the second set of themes concerns where these four articles are pointing us to go in the future. In doing so, I recognize just how difficult studying the effects of something like the Great Recession on young people can be. It is a true challenge. Because no one (well, almost no one) predicted the Great Recession beforehand, we have to rely on "accidental data", or data collections that just happened to be underway when the Great Recession unfolded. By definition, then, these data collections were not actually designed to study the Great Recession. The implicit cross-cultural comparisons in this collection of four articles adds another layer of complexity, as comparing and contrasting the findings of four sets of accidental data with different measurement and sampling strategies is a tall order indeed.

\section{What was found}

Reviewing the findings of the four studies and looking for commonalities, several things stick out to me.

First, the Great Recession hit young people hard, but it was not necessarily a complete disaster across the board. 
The researchers and research teams featured in this Special Section assessed recession effects in different ways, both in terms of the economic hardships of individual families (e.g., Schoon in the United Kingdom) and through broader comparisons of historical timing before and after the Great Recession (e.g., Staff and colleagues in the United States). In general, both the direct and indirect effects of the Great Recession, however measured, on young people were significant, but they could best be characterized as moderate in magnitudesizeable, yes, but not as big as might have been expected or feared. This generalized attenuation of recession effects across the studies, likely reflects the fact that sample averages subsumed substantial variability in effect size. The Great Recession and its associated family hardships mattered a great deal in some segments of the population and less so in others. For example, boys appeared to be more vulnerable than girls in the United Kingdom (Schoon) and Minnesota (Mortimer et al.). As another example, in Germany, young adults who were single appeared to be more vulnerable than those who were partnered (Groh-Samberg et al.). These patterns of variability bring to mind Elder's (1999) pioneering study of children growing up during the Great Depression of the 1930s in the United States. His influential work, which is a clear foundation of the studies in this Special Section, revealed how both inequality and resilience converged to inject diversity into (and ultimately mitigate) the overall effects of the economic crisis on children.

Second, how young people experienced the Great Recession was deeply rooted in their family histories, especially parents' pasts.

Mortimer and her colleagues reported that the negative association between family economic problems and recession-era youths' future aspirations in Minnesota was exacerbated when parents had histories of unemployment. This finding suggests that parents became sensitized to hard times through their own personal histories of hardship in ways that might have allowed pessimism to filter down to their children. Similarly, Schoon found that growing up with persistently unemployed parents increased the odds of young people being out of work and school during the Great Recession in the United Kingdom, and Groh-Samberg and colleagues found that seemingly independent young adults' "real" experiences of poverty - before and after the Great Recession in Germany - were predicated on how much they could draw on their parents' financial resources. The connected socio-economic trajectories of parents and youth in these articles represent linked lives, to borrow a term from life course theory. Of course, the ability to delve into these linked lives was constrained by the availability of data, as measurement of family histories was limited across the data sets. Finer-grained family histories - encompassing parents work, education, financial, relationship, and residential statuses and transitions - need to be considered, but such histories put great demands on data collection.

Third, some of the variability in the consequences of the Great Recession for young people resulted from psychological buffers.

The perceptions, attitudes, and general orientations of young people seemed to condition how they lived through the Great Recession and any associated family economic troubles, evidence of individual differences within contextual variation. We saw an example of such buffering in the academic expectations of young people in the study by Schoon and colleagues in the United Kingdom. When young people held onto more positive dreams of the future, their parents' economic troubles posed less risk to their socioeconomic functioning as young adults. The study by Mortimer and colleagues in Minnesota revealed an interesting twist to this buffering pattern within families. The academic orientations of parents in Minnesota, back when they had been adolescents themselves, appeared to be a buffer protecting their children from the risks of their economic troubles many years later. Something that they developed as young people helped their own children later on. These findings drive home the fact that individual people may react to the same situation in very different ways, another way that the four studies in the Special Section align with life course theory and other developmental perspectives.

Fourth, recovery is coming slow and will likely take a while.

Technically, the Great Recession ended in the late 2000s (2009 in the U.S. according to the National Bureau of Economic Research, which decides such things). Yet, the "felt" recession has lingered far 
longer and continues even today. Significantly, none of the longer-term studies in this Special Section indicated any real improvement in young people's fortunes as the Great Recession supposedly faded. The findings by Staff and colleagues in the U.S. that teen unemployment did not rebound when the economy rebounded were particularly striking in this regard. When will the recovery happen? To answer this question, we can look at studies of the consequences of past recessions on socio-economic attainment by economists in the U.S., Canada, Japan, and other countries. These studies generally show that young people who enter adulthood during recessionary times generally do not make up their lost earnings and job statuses for many years or even decades; some do not at all (Oreopoulos, von Wachter, \& Heisz, 2012; Genda, Kondo, \& Ohta, 2010; Kahn, 2010). That the Great Recession was so much more severe than these past recessions, therefore, is sobering indeed.

\section{Where to go now}

The four studies in this Special Section did have some limitations, and they also leave many open questions. In these ways, they offer suggestions about where future research on the Great Recession (and any future recessions) can take us.

First, the Great Recession is an economic event but one with non-economic outcomes that need to be explored.

Because any economic downturn, especially one as dramatic as the Great Recession, are so deeply relevant to the short- and long-term socio-economic circumstances of families, there is an understandable tendency to view recession effects on young people through the lens of human capital, occupational status, and other markers of socio-economic functioning. Despite many differences in focus, setting, and approach, all four of the studies conceptualized youth outcomes in such terms, considering aspects of educational attainment, income and earnings, and employment. Certainly, these outcomes are important, even crucial, but they do not represent the only ways in which young people might be vulnerable. Mental health is clearly a concern during a major (and cataclysmic) historical event like the Great Recession, as are other aspects of socio-emotional functioning that may change in or out of sync with changing economic fortunes. I would also encourage more consideration of how the effects of the Great Recession have gotten under the skin; in other words, using biomarkers and other physiological data to understand the residue of the Great Recession within the body (McDade, 2001).

Second, the Great Recession can also be thought of as a local phenomenon.

The four studies in this section captured the Great Recession in a macro-level way (e.g., historical timing in the studies by Staff and colleagues in the United States and by Groh-Samberg and colleagues in Germany) or in a micro-level way (e.g., parents' unemployment and financial problems in the studies by Mortimer and colleagues in Minnesota and Schoon in the United Kingdom). The meso-level middle ground of local economic conditions (broadly defined as states or provinces or more narrowly defined as metropolitan areas or neighborhoods) was not taken into account in any of the articles. In the U.S., for example, the Great Recession was a highly regional and state-specific phenomenon. The upper Midwest and states with strong energy industries weathered the storm well (e.g., South Dakota and Texas), but many states that are dependent on heavy manufacturing and/or had real estate bubbles fared poorly and have continued to struggle after the recession officially ended (e.g., Nevada and Michigan). Even within states, rural, suburban, exurban, and urban areas fared differently (Bureau of Labor Statistics, 2012). That kind of variation is lost when state-, city-, and zip code-level economic indicators are not used to study recession effects on young people and their families.

Third, valuable country-level comparisons of young people in the Great Recession can be taken deeper.

Essentially, the four articles in this Special Section line up three country-specific pictures of young people during the Great Recession that readers can then compare to each other. This cross-national comparison could be made more direct and systematic in the future by harmonizing data sets across countries through new statistical techniques (e.g., integrated data analysis, or IDA; see Curran \& Hussong, 2009), pooling all data across countries into the same sample, interacting country-specific identifiers in this pooled sample with recession markers (e.g., cohort timing, economic conditions), 
and then including various country-level characteristics as mediators of any observed differences in recession effects across countries. Through such an approach, we can better understand why youth in one country fared better (or worse) during the Great Recession than youth in another country, paying attention to how countries might differ both prior to and during the Great Recession, that would shape how it was experienced by young people. Of course, this approach also requires that a more substantial number of countries be included, not just the three featured here. It also requires some sacrifice of the depth of data and scope of sampling, as many differences in the extant data sets would have to be addressed. In other words, there are extant data to be harmonized after the fact, but the ideal scenario would be to coordinate data collections across countries moving forward, to avoid some of these limitations to systematic and in-depth cross-country analyses.

Fourth, policy relevance should be assessed when studying both risk and resilience in young peoples' experiences of the Great Recession.

As already noted, some of the most interesting protective factors (i.e., something that buffers against the negative effects of a risk factor) in the four studies in this Special Section were psychological or attitudinal in nature. Theoretically, these factors are important to the life course, but thinking about how they might be manipulated (e.g., developed, enhanced) through policy intervention is challenging.
If academic orientation matters, how do we promote academic orientation? This question is a challenging one, realistically. Compared to more concrete contextual factors like school organization, social services, or community resources, these more psychological or interpersonal buffers do not seem altogether policy amenable. Yet, the practical value of Great Recession research will be increased if we seriously consider policy amenability when building our conceptual models-not just what matters to youth outcomes but also what we can do something about. Policy relevance is not the only value of a study, of course, but it is a value that warrants attention.

\section{Conclusion}

To end, I want to go back to the beginning, to that economist's prediction that today's youth are scarred and could very well be a lost generation because of the Great Recession that they have endured during such a critical phase of life. The truth is that we do not yet know if this dire prediction is true, but we will know in the future if studies like those by Mortimer, Schoon, Groh-Samberg, Staff, and their colleagues continue and go deeper. They give us a window into the ramifications of a specific historical event (one that likely will repeat itself in the future if history is a guide) while also opening up a window into far more general life course dynamics. As such, they are simply good social science.

\section{References}

Bureau of Labor Statistics. 2012. The recession of 2007-09. www.bls.gov/spotlight

Curran, P. J., \& Hussong, A. M. (2009). Integrative data analysis: The simultaneous analysis of multiple data sets. Psychological Methods, 14, 81-100. http://dx.doi.org/10.1037/a0015914

Elder, G. H. Jr. (1999). Children of the Great Depression: Social change and life experience $\left(25^{\text {th }}\right.$ anniversary edition). Boulder, CO: Westview.

Estes, A. C. (2011). More signs that American youth are a lost generation. The Atlantic. September 22, 2011.

Genda, Y., Kondo, A., \& Ohta, S. (2010). Long-term effects of a recession at labor market entry in Japan and the United States. Journal of Human Resources, 45, 157-96. http://dx.doi.org/10.1353/ihr.2010.0005

Groh-Samberg, O., \& Voges, W. 2014. Precursors and consequences of youth poverty in Germany. Longitudinal and Life Course Studies 5, 151-172. http://dx.doi.org/10.14301/llcs.v5i2.281

Grusky, D., Western, B., \& Wimer, C. (Eds). (2012). The Great Recession. New York: Russell Sage.

Kahn, L. B. (2010). The long-term labor market consequences of graduating from college in a bad economy. Labour Economics, 17, 303-16. http://dx.doi.org/10.1016/j.labeco.2009.09.002 
McDade, T. W. (2001). Lifestyle incongruity, social integration, and immune function in Samoan adolescents. Social Science and Medicine, 53, 1351-1362. http://dx.doi.org/10.1016/S0277-9536(00)00414-7

Mortimer, J.T., Zhang, F.L., Hussemann, J., \& Wu, C-Y. 2014. Parental economic hardship and children's achievement orientations. Longitudinal and Life Course Studies 5,105-128. http://dx.doi.org/10.14301/llcs.v5i2.271

Oreopoulos, P., von Wachter, T., \& Heisz, A. (2012). The short- and long-term career effects of graduating in a recession. American Economic Journal: Applied Economics, 4, 1-29.

Schoon, I. 2014. Parental worklessness and the experience of NEET among their offspring. Longitudinal and Life Course Studies 5, 129-150.

Staff, J., Johnson, M.K., Patrick, M., \& Schulenberg, J. 2014. When teenage work disappears. Longitudinal and Life Course Studies 5, 173-188. http://dx.doi.org/10.14301/llcs.v5i2.275

Silbereisen, R. (2005). Social change and human development: Experiences from German unification. International Journal of Behavioral Development, 29, 2-13. http://dx.doi.org/10.1080/01650250444000478 
